\title{
La Reconceptualización del Trabajo Social en Colombia: análisis histórico-crítico de las décadas de 1960-1970
}

\section{Juan Pablo Sierra-Tapiro}

Doctor en Servicio Social, Trabajador Social

Universidad del Estado de Rio de Janeiro. Rio de Janeiro, Brasil

https:/ / orcid.org/0000-0002-0536-4319• juan.tapiro@uerj.edu.br

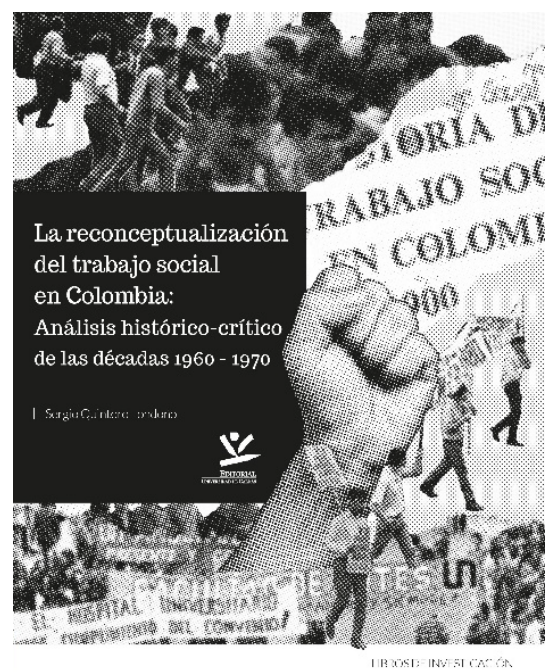

\author{
Quintero Londoño, Sergio ${ }^{1}$ \\ La Reconceptualización del Trabajo \\ Social en Colombia: Análisis histórico- \\ crítico de las décadas de 1960-1970. \\ Colombia: Editorial Universidad de \\ Caldas.
}

ISBN: 978-958-759-277-1

2021

360 págs.

\section{Presentación}

Esta reseña retoma la base del comentario pronunciado en el lanzamiento del libro $L a$ Reconceptualización del Trabajo Social en Colombia: Análisis histórico-crítico de las décadas de 19601970, realizado de manera virtual el 19 de octubre de 2021, organizado en el marco de la conmemoración del día clásico del Trabajo Social en Colombia, por el Programa de Trabajo Social de la Universidad de Caldas con la editorial de esa universidad.

1 Profesor de la Universidad de Caldas. Doctor en Servicio Social de la Universidad del Estado de Rio de Janeiro. Integrante del Colectivo de Trabajo Social Crítico Colombia.

Recibido: 05/08/2021| Aprobado: 24/10/2021 | Publicado: 01/01/2022

(1) (1) (2)

Esta obra está bajo una Licencia Creative Commons Atribución-NoComercialCompartirIgual 4.0 Internacional.

\section{¿Cómo citar este artículo? / How to quote this article?}

Sierra-Tapiro, J. P. (2022). La Reconceptualización del Trabajo Social en Colombia: análisis histórico-crítico de las décadas de 1960-1970. Prospectiva. Revista de Trabajo Social e intervención social, (33), 341-347. doi: $10.25100 /$ prts.v0i33.11736. 
Sierra-Tapiro

Quisiera destacar la alegría de presentar y reseñar el libro de un compañero, camarada y amigo, con quien nos conocemos hace más de 14 años. Hemos compartido en procesos como el Colectivo de Trabajo Social Crítico Colombia y el Movimiento Político y Social Marcha Patriótica; también convivimos un tiempo juntos en Brasil, y hemos sido cómplices de diversas apuestas comunes.

Este libro es un producto que sintetiza parte de más de 10 años de investigación, desde el Trabajo de Grado en la Universidad de Caldas (cuando tuve la oportunidad de ser su asesor al final de ese proceso en 2011), pasando por su disertación de Maestría en la Universidad Federal de Rio de Janeiro, defendida en 2014 (orientado por el profesor Luis Acosta), y especialmente su tesis de Doctorado en la Universidad del Estado de Rio de Janeiro, defendida en 2018 (orientado por la profesora Marilda Iamamoto). Por tanto, lo que se nos presenta es la aproximación que se ha logrado hasta ahora -después de una rigurosa investigación- de uno de los procesos más importantes de la profesión, cuyo legado sigue vigente y se expresa de diversas maneras en las apuestas que se asumen como críticas en Trabajo Social.

Con seguridad, este libro será un referente en los debates contemporáneos sobre el Movimiento de la Reconceptualización en Colombia, tema muy comentado pero poco estudiado e investigado, como el propio autor lo evidencia; contribuyendo también a los debates en toda la región. Es un importante aporte para el análisis de ese proceso, con nuevos elementos inexplorados hasta ahora, y con muchas pistas para seguir ampliando y profundizando en estudios e investigaciones futuras.

\section{La perspectiva de análisis del autor}

Quisiera empezar rescatando la perspectiva que se asume en la realización del trabajo de investigación, donde la base de su análisis, que atraviesa todo el libro, es la mediación entre la crisis capitalista -refiriéndose al inicio de la crisis estructural del capital- y la Reconceptualización, teniendo como fundamento la crítica de Marx a la economía política².

Contribuye a superar una falsa dicotomía, que se presenta en muchas ocasiones en los estudios del Trabajo Social en Colombia y la región, en la relación entre el movimiento de la sociedad pensado en sus determinaciones estructurales y los sujetos (colectivos e individuales) que hacen parte de la historia, en este caso en particular, con un énfasis en las mediaciones con la profesión.

2 El último capítulo de su tesis doctorado, que no se incluye en este libro, es precisamente una aproximación a la teoría crítica de la economía política, especialmente a la teoría del valor-trabajo en Marx. 
Sierra-Tapiro

En consecuencia, el autor nos presenta una aproximación a las mediaciones entre la crítica de la economía política y el movimiento de la lucha de clases en la sociedad capitalista en el mundo, en América Latina y en Colombia, como base para entender y pensar las trayectorias, debates y procesos al interior de la profesión.

Su análisis es asumido desde el método dialéctico-materialista, desde una perspectiva de totalidad, lo que le posibilita analizar la relación entre estructura y sujeto, lo cual concretiza a partir del análisis de fuentes bibliográficas secundarias, pero también aproximándose a fuentes primarias, recogiendo documentos históricos elaborados al calor del Movimiento de la Reconceptualización en Colombia entre las décadas de 1960 y 1970, y que además contó con la posibilidad y oportunidad de realizar entrevistas e intercambios con protagonistas de ese proceso en algunos países de la región y varias ciudades de Colombia (esta diversidad de fuentes es uno de los principales elementos inéditos de este trabajo).

Además de asumir la crítica de Marx a la economía política y el método dialécticomaterialista, Sergio Quintero Londoño, expresa abiertamente una perspectiva revolucionaria de la clase trabajadora, con las mediaciones necesarias para pensarse desde ahí al interior de la profesión, superando perspectivas mesiánicas, planteando el debate del horizonte del proyecto ético-político profesional (como parte del proceso de renovación crítica del Trabajo Social).

\section{La exposición del libro}

El libro está organizado en una exposición de ocho capítulos, además del prólogo, realizado por la profesora Marilda Iamamoto, la introducción y unos breves comentarios sobre el procedimiento de investigación.

En el primer capítulo el autor expone el ascenso y crisis del capital, con un especial énfasis en la dinámica del capitalismo monopolista en el pos-II Guerra Mundial hasta la década de 1970, destacando el papel del Estado, las relaciones capitalistas en la periferia y la crisis capitalista que inicia entre finales de la década de 1960 y la primera mitad de la década de 1970.

En el segundo capítulo se expone el Movimiento de la Reconceptualización en ese proceso, entre el ascenso y la crisis capitalista, haciendo referencia a cómo se desarrollan debates al interior de la profesión en América Latina, en el marco de los Congresos Panamericanos de Servicio Social y los Seminario Regionales Latinoamericanos de Servicio Social, evidenciando sus contradicciones y movimiento dialéctico, como parte de las disputas al interior de la Reconceptualización; finalmente presenta lo que denomina los 
Sierra-Tapiro

principales actores (sujetos colectivos e individuales) y consecuencias de la Reconceptualización.

En el tercer capítulo, se realiza una aproximación a la crisis capitalista y la lucha de clases en Colombia, partiendo desde las contradicciones políticas que se expresaban en el periodo denominado como "La Violencia", pasando por los procesos de autodefensa campesina y las organizaciones guerrilleras, hasta las particularidades de la lucha de clases en el "Frente Nacional" (1958-1974); presentando un destaque sobre el movimiento estudiantil que en su momento se manifiesta contra lo que denomina la modernización de la Universidad.

En los cuarto, quinto, sexto y séptimo capítulos, el autor presenta las particularidades del Movimiento de la Reconceptualización en Bogotá, Medellín, Cali y Manizales, respectivamente. En estos capítulos se encuentra lo más rico e inédito de la exposición de Sergio Quintero Londoño, a partir de una reconstrucción histórica del desarrollo de este proceso en estas ciudades. Se evidencia la diversidad al interior de ese Movimiento, el autor nos propone elementos de reflexión novedosos, problematizando supuestos poco sustentados, que han llevado a asumir la Reconceptualización como un proceso homogéneo.

El octavo capítulo, a manera de conclusiones en abierto, es una síntesis de las tendencias generales y el legado de la Reconceptualización, destacando un debate sobre el proceso de "incorporación" del marxismo al Trabajo Social, y el significado histórico y contemporáneo de la Reconceptualización.

\section{Destaques y debates}

Quisiera realizar cinco destaques de los elementos que considero el libro nos trae como contribución para la reflexión y debate en la profesión, así como algunos elementos para ser problematizados y necesariamente profundizados:

1. El libro presenta un cuidado en la aproximación de las particularidades del desarrollo capitalista regional en NuestrAmérica y en Colombia, exponiendo elementos de análisis muy importantes respecto a su carácter dependiente (aquí se propone como necesario el estudio de la Teoría Marxista de la Dependencia); haciendo énfasis en la dimensión coercitiva del Estado colombiano, brindando pistas para entender su carácter oligárquico-burgués; y también planteando elementos sobre las particularidades de la lucha de clases.

Importante destacar que el análisis del autor parte desde la década de 1940 (posII Guerra Mundial), para poder entender las dinámicas de las décadas de 1960 y 1970, superando un límite que muchas veces se presenta al estudiar la 
Sierra-Tapiro

Reconceptualización solamente a partir de los procesos sociales en el contexto de esas dos décadas.

Aquí, a mi manera de ver, incluso conociendo sobre la trayectoria académica y política del autor, y dado el énfasis en la dimensión coercitiva del Estado, faltó una mayor profundización respecto al análisis y exposición de la estrategia contrainsurgente, tanto a nivel regional como nacional -lo que además brindaría pistas para pensar en la actualidad.

2. Sobre la Reconceptualización, insisto en destacar el análisis del movimiento dialéctico que se presenta en los debates en diversos eventos y al interior de la formación profesional; así como la vigencia de la Reconceptualización, en términos de debates que surgieron en ese Movimiento y que aún están presentes. Lo que posibilita entender la heterogeneidad (y no homogeneidad) al interior de ese movimiento profesional, en el cual el Trabajo Social tuvo una primera aproximación al marxismo (Sergio hace un análisis para evidenciar qué marxismo fue ese), pero de ninguna manera implica que la Reconceptualización "fue marxista" como muchas veces se expresa en el sentido común profesional.

Así mismo, esa heterogeneidad implica el reconocimiento de la diversidad al interior de la profesión, y por tanto la necesaria pluralidad en los procesos de debate y formación profesional, asumiendo, incluso para la contemporaneidad, que existe la disputa por una hegemonía en la dirección de la profesión en cada país y en la región -donde todas las perspectivas, también el marxismo, deben tener espacio.

3. En este mismo sentido, el libro trae aportes para problematizar debates que surgieron en la Reconceptualización y que aún en la actualidad tienen plena vigencia, por ejemplo, el debate sobre la "especificidad" del Trabajo Social como una ciencia social o una disciplina social, constituyendo la denominada perspectiva endogenista-epistemologista, que en la actualidad se presenta con nuevas formas. Esto tiene todo que ver con la necesidad de debatir los fundamentos teóricos-metodológicos-políticos del Trabajo Social (desde su surgimiento, en la Reconceptualización y en la contemporaneidad), lo que a su vez contribuye en la superación de una falsa dicotomía entre cientificidad e ideología (en un sentido amplio de visión de mundo), que se expresaría en la supuesta diferenciación entre quienes asumen una perspectiva disciplinar y quienes asumen una perspectiva politicista de la profesión. 
Sierra-Tapiro

4. Un debate en abierto, con lo planteado por el autor, es que entre los actores que propone está el Centro de Estudios Latinoamericanos en Trabajo Social (CELATS) y la Revista Acción Crítica como uno de los vehículos de los debates de la Reconceptualización.

Al respecto, la exposición contiene una contradicción, ya que se tiene claridad que el CELATS surge en 1975 y la Revista Acción Crítica se empieza a publicar en 1976, pero la Reconceptualización, en términos regionales entra en crisis desde 1972-1973 (donde es fundamental el contexto de expansión de las dictaduras cívico-militares) y ya en la segunda mitad de la década de 1970 se estaría en otro momento, de balances y nuevos procesos desde diversas perspectivas (modernizadoras/conservadoras y críticas), más allá de la Reconceptualización, que continuaron su desarrollo en cada país según sus particularidades en las décadas siguientes. Para el caso Colombiano, según lo que expone Quintero en el libro, esa crisis de la Reconceptualización se habría presentado precisamente en los primeros años de la segunda mitad de la década de 1970. Por tanto, en realidad tanto el CELATS como la Revista Acción Crítica, a rigor, no harían parte de ese Movimiento, lo que no retira su importancia, para entender esa transición y el legado de la Reconceptualización a las tendencias y debates profesionales posteriores.

5. Finalmente, siendo el Trabajo Social una profesión mayoritariamente compuesta por mujeres, una reflexión que me llamó la atención por su ausencia, a pesar que Sergio apunta algunos elementos, pero ciertamente no es uno de los componentes que tenía por objeto en su investigación -y seguramente no apareció con fuerza en su rastreo- es si hubo o no, o qué tanto hubo, una aproximación entre el movimiento de las mujeres, la denominada "segunda onda feminista" y la Reconceptualización; lo que ciertamente es una problematización más que para el autor, para quienes continúan estudiando e investigando sobre la Reconceptualización, asumiendo un debate que cada vez toma más fuerza para pensar el Trabajo Social en la contemporaneidad, y que también se expresa desde diversas perspectivas.

\section{A manera de conclusión}

Este libro es necesario y pertinente en los debates de la profesión, porque nos trae un aporte para entender que la Reconceptualización no se quedó en el pasado, fue un proceso muy potente que fue truncado, por lo tanto es necesario seguirla estudiando, en sus contribuciones, contradicciones y limitaciones; no para repetir esa experiencia, sino para continuar la apuesta por una renovación crítica del Trabajo Social en Colombia y NuestrAmérica. 
Seguramente, este libro se constituirá en una referencia del debate profesional, especialmente con quienes vivieron ese proceso, pero también quienes nos hemos aproximado a su estudio. No es un libro conclusivo, sino que por el contrario, abre, amplía y profundiza muchos elementos para nuestras reflexiones colectivas, y da pistas para seguir investigando, tanto las experiencias expuestas en este libro, como otras que no.

Finalmente, me parece importante destacar la oportunidad de la publicación de este libro de investigación de más de 300 páginas, por la Editorial de la Universidad de Caldas, en tiempos en que la (i-)racionalidad neoliberal, el productivismo, y la superficialidad, se imponen cada vez con más fuerza en la academia.

\section{Referencias bibliográficas}

Quintero-Londoño, S. (2021). La Reconceptualización del Trabajo Social en Colombia: Análisis histórico-crítico de las décadas de 1960-1970. Colombia: Editorial Universidad de Caldas. 